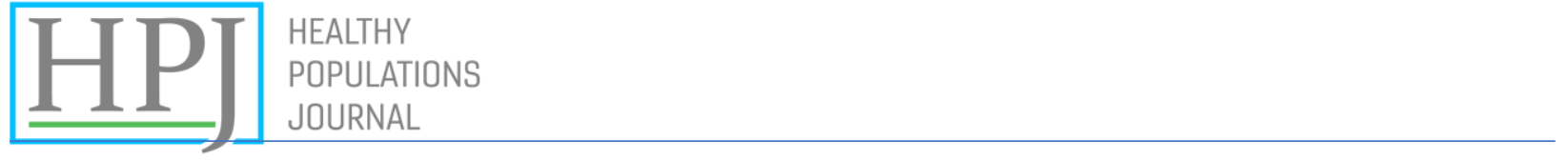

\title{
Short Story
}

\section{The Revival}

Kevin Mercurio, MSc

Trinity College, Dublin

DOI: https://doi.org/10.15273/hpj.v1i2.11081

\begin{abstract}
About the Author
Kevin is a 1st year PhD student at Trinity College Dublin researching the impact of microRNAs on the gut microbiome. Previously, he completed his MSc and BSc in Biochemistry at the University of Ottawa. He's an avid blogger, published fiction writer and host of the Metaphorigins Podcast. He's performed science communication pieces on national and regional platforms, and volunteers for science initiatives like Science Slam Canada and the Scholars Ireland Program for underrepresented youth.
\end{abstract}

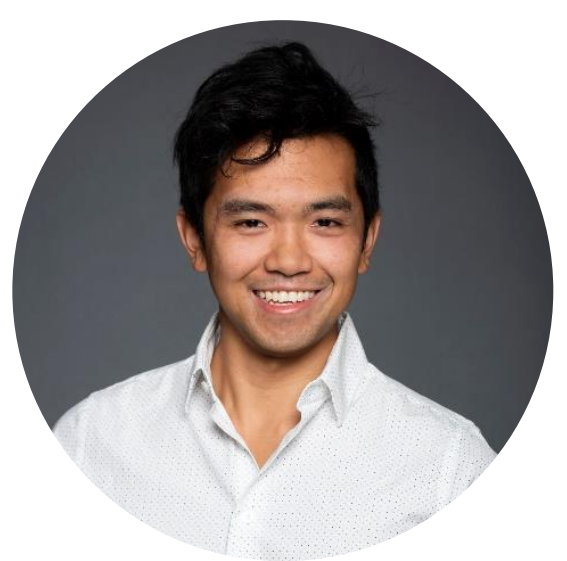

\section{About the Story}

The Revival was written after a conversation with my brother about his experience as a gay youth in high school. This conversation, despite being difficult, permitted the both of us to reflect on society as it moves into a more progressive direction. The story itself is written in the style of American writer Shirley Jackson, attributed to genres of mystery, because of the lack of understanding towards sexuality and gender identity. One half of the story focuses on sexuality, while the other half highlights the burdens women have at all stages of their life. In the story, Jennifer is encouraged to remain at home rather than pursue a field in which women are underrepresented. Jennifer is also marginalized at her workplace by parents who do not reconcile her looks with societal archetypes of professionals in healthcare. Though changing, this experience is felt by women across the globe, and requires a cultural shift in not just acceptance, but awareness of where our own biases lie. The story assumes circumstances of mental health and suicide, concerns within people lost in this volatile system. Yet, until we address these concerns openly, cultural progress cannot be made. 
Good morning everyone.

\section{The Revival}

Before the session begins, I would like to say a few words.

On behalf of John and Jennifer, I would like to thank you for attending this annual service. It would really mean the world to them to see you all here, in one place, despite the circumstances that brought us here today.

Today is the Revival. It is also the first time I have had the pleasure of meeting a vast majority of you. As their father, it saddens me that we only came together at such a time. However, based on our many conversations today, I can see why John and Jennifer have called you their extended family.

What I would like to do is to talk a little bit about the lives of these two extraordinary people in front of you. Perhaps, as we reflect collectively on the moments that were shared, this can give each of us a bit of closure, even a bit of empathy, so that we can understand my two favourite minds. Perhaps this may even allow us to reflect on our own lives and readjust, such that we can change the outcome of our own personal stories.

The happiest day of my life was when the twins were born. It's funny... The worst day of my life is also this same day, because the love of my life died giving birth to these very same twins. This was funny because life doesn't really prepare you for such a rare event, or any rare events for that matter. No, biased life seems to favour an archetype. And, coming from the average tall, white, straight man, you can believe me when I say that.

But I digressed. Any single, seemingly lonely parent will tell you that raising two newborns on your own is a feat equivalent to climbing an arduous mountain. Well, no expedition is complete without an experienced climber as their guide. That honorary title goes to my mother, Eleanor, who was the saving grace that helped take the twins from that blank slate to the magnificent people you all know.

I remember during their very first birthdays... It was so surreal to have many of you come dressed in blue and pink, their favourite colours. Let me tell you something... Another advantage of having twins is that you always get to have two cakes! A memorable moment, as many of you know, is John's face just covered in chocolate cake while Jennifer, clean as a whistle, slowly ate her vanilla cake sprinkled with colourful candies. The amount of trucks and dinosaurs, and dolls and tea sets now stacked away in my basement could put failing toy stores back in business!

Fast forward five years... Oh! Their first day of school. Do you remember that, Mom? How difficult it was to put them into their school uniforms. I think they gave John a pants size too big and Jennifer a dress size too small. Something was off, I'd say! And that entire car ride there was just full of groaning and complaining; longing for the lazy days, or concerned about meeting new people to make friends. Picking them up was such a contrast! John, just running, and I mean running, into the car. And then there was Jennifer, smiling while carrying her new textbooks. You can tell who had a good day and who just wanted to come home to their toys.

Let's jump ten years, to the end of high school. Everyone says that the teenage years are the worst years as a parent. They suddenly go from wanting you to wanting little to do with you. It was difficult. John was getting a football scholarship to Dalhousie University, and Jennifer was still a bit confused about what she wanted to do, where she wanted to go. She couldn't decide whether to go to Europe for an engineering degree or stay in town and do nursing. I wanted my baby girl close to my side, and eventually I ended up persuading her to go into nursing. Ultimately, I think she made the right choice, because she became the best goddamn nurse in the province. 
Even though he was not the honour roll student, John did incredibly well through university, rising up the ranks of his football team and ending up being the star quarterback. He led his teams to win two consecutive championships, at the regional and finally the national level. It was at this point that I wish John had talked to me about his mental issues. Many of you probably know better than his old man, but John often denied his homosexuality, and his demeanour granted his fellow teammates ample opportunity for derision.

This was about the time when Jennifer started to... How do I put this... Change. I mean, back in her teenage years before the surgery, she would occasionally play in some punk band as their lead drummer. They called themselves "The Hirschfeld Committee", a strange name in my opinion. I asked her about it one day and she told me I needed to read up on my history. I tell you, when your kid replies with "read some history", sometimes all you can really do is laugh.

At this point, Mom was really worried. Her Catholic son had raised a gay son and an upcoming transgender daughter. Mom would say I was the "Founder of the LGBTQ Movement". I don't know why, but that comment stuck with me. I mean, Mom, was that supposed to be an insult? Even at work, I was being treated differently. For instance, the guys over at the plant were always talking about how sexy their wives are, how awesome their sons are in soccer or football, like John, or how adorable their daughters are in baking and dancing. You know, family stuff. Then I walk into the room, and immediately it became silent. And I mean silent. So silent, that I could almost hear their eyes staring at me. Nobody cared to ask how John and Jennifer were doing anymore. Why is that?

John finished his schooling in engineering and applied to his first job as an electrical engineer for Stonewall Solutions. Yes, our famous John - the Fashion Designer - was first an electrical engineer. Jennifer was also working as a nurse at the Pediatric Disability and Blood Management (PDBM) Hospital. Although she was the best goddamn nurse in the province, Jennifer later quit due to, and I quote, "inappropriate commentary by many of the children's parents". The twins hated this point in their lives. What was happening here? I couldn't figure it out and I was slowly going insane.

One night, six years after my twins were carelessly removed from this world, I was sitting at the dining room table with a glass of milk and took a sip. It had spoiled. After spitting it out in disgust I thought, "How do I know that this spoiled milk is bad for me"? I replied, "Well, because my body senses that I ingested something harmful and makes me spit it out". This experience, learned long ago, makes us remember that spoiled milk has a bad taste and texture. We label this type of milk as bad food.

Have you ever thought about how much we label things? How our brains categorize everything into specific groups? We do that with food, animals, cars, words and even people. We give people labels that describe their weight, their height, their personality. And all this seems strangely normal. So normal, in fact, we extend these labels beyond what they are meant for, extending them into our own personal lives. We label those who love the opposite sex as heterosexual and those who love the same sex as homosexual. Why did these words have different emotions attached to them? Why did heterosexuality seem average and bland while homosexuality seemed interesting and peculiar? Does this labelling not create majorities and minorities? And let's not get started on the inquisitiveness of, for example, a biological man who feels like a woman but is attracted to men...

Why do we need to label things anyway? It always comes down to human routine. A man walks into a room, sees a woman he likes, talks to her, dates her, marries her, has kids, etcetera. Obviously, life isn't as simple as that but realize that this is the normal story we were bombarded with throughout history. Who told us this was the only way of doing things? Why are we so accustomed to labelling this as the norm? Did the man even have a chance to decide that he likes women? Put even more broadly, what circumstances brought the woman to the room in the first place? 
Let's look at John. John was born a boy. I raised him like anyone would raise a boy and encouraged him to like boy things. I rewarded boy behaviour. I overlooked any suggestion that John could think for himself and be curious about how a boy should grow up to be a man.

And what about Jennifer? Jennifer was born a girl. I cared for her like any father would care for their little girl. I recommended that she learn from close female role models like Mom. I clothed her like how most girls seemingly enjoy being clothed. I disregarded any notions that Jennifer could possibly be interested in the habits and activities that boys seemingly like to do.

That's just what we do. That's the only thing life prepares us for. Our society is unequipped to raise children any different than our ancestors did back in history. Can we remain this way? Would John and Jennifer have had a better life if they could choose how to live without outside influences? If we continue to be governed by people of the past, how could this possibly change?

For the Revival, we have voted to give John and Jennifer another chance to be a part of our new society. A society that has finally surpassed labelling our personal differences. A society apathetic to old romantic endeavours and primitive judgements about our capabilities to function in our gender roles. A society built on contributing to the goodness that life has to offer, and the freedom of personal development granted through equity and diversity. We have given them the hindsight of their future, and the wisdom that comes with it at an early age, so that they can decide to live the life they truly desire.

Back from the dead, please join me in welcoming my two favourite minds, John and Jennifer!

And as the congregation stood and applauded, there was a loud electrical shock that signalled the start of the re-animator. In less than 30 seconds, the two decomposing bodies at the front of the room shrunk down to healthy, intelligent adolescents. 